\title{
IDENTIFICATION OF KEY EFFECTS CAUSING WEAK PERFORMANCE OF ALLERGEN ANALYSIS IN PROCESSED FOOD MATRICES
}

\author{
K. TöröK*, L. Hajas, V. Horváth, E. Schall, Zs. Bugyi and S. TÖmösKöZi \\ Department of Applied Biotechnology and Food Science, Faculty of Chemical Technology and Biotechnology, \\ Budapest University of Technology and Economics, H-1111 Budapest, Szent Gellért tér 4. Hungary
}

(Received: 6 November 2014; accepted: 21 February 2015)

\begin{abstract}
The weaker performance of generally used analytical methods for allergen analysis in processed foods can be connected to protein denaturation. To understand the nature of protein denaturation processes, experimental but realistic model matrices (corn starch based mixture, hydrated dough, and heat treated cookies) were developed that contain a defined amount of milk, egg, soy, and wheat proteins individually or in combination. The protein subunit composition was investigated in every processing phase, i.e. after mixing, dough formation, and baking. SDS-PAGE measurements were carried out to monitor the protein distribution of sample food matrices in non-reducing and reducing gels. The results clearly show that the highly decreased protein solubility is caused by denaturation, aggregation, or complex formation, which are the most significant factors in poorer analytical performances. Solubility can only partly be improved with the application of reducing agents or surfactants, and the rate of improvement is depending on the proteins and the matrices.
\end{abstract} PAGE

Keywords: food allergens, celiac disease, effects of heat treatment, processed model food matrices, SDS-

Food induced hypersensitivity reactions are important food safety issues. A high proportion of hypersensitivity reactions are triggered by eight food groups: cereals containing gluten, crustaceans, egg, fish, peanuts, soybeans, milk, tree nuts, and sulphites. In order to reach an asymptomatic condition, patients should avoid the problematic food components during their whole life (TAYLOR \& HefLE, 2001). To provide information for the consumers, food manufacturers in the European Union are obligated to label the presence of 14 components that can induce hypersensitivity reactions (EU, 2011).

For the determination and quantification of these components, the most prevalent analytical method is ELISA, because of its sensitivity, specificity, and easy handling. The analytical methods should be able to extract and quantify the target proteins from different matrices. Furthermore, in complex food systems more allergenic/toxic compounds can be found simultaneously, therefore the development of methods capable of detecting multiple components is reasonable (BLAis et al., 2003; HeicK et al., 2011).

Previous studies (BugYI et al., 2010; Fu et al., 2010; TÖRÖK et al., 2014a,b) show that quantification of allergens from processed food matrices using ELISA methods may lead to incorrect results. The proteins triggering food allergies and celiac disease can undergo chemical and structural changes during the processing steps, affecting solubility and immunoaffinity. At the same time, it is not known whether a decrease in ELISA detectability

\footnotetext{
* To whom correspondence should be addressed.

Phone: +36-1-463-1153, fax: +36-1-463-3855; e-mail: ktorok@mail.bme.hu
}

0139-3006/\$20.00 @ 2016 Akadémiai Kiadó, Budapest 
is accompanied by a decrease of biological activity (i.e. the ability to trigger adverse reactions). Understanding the behaviour of allergenic proteins targeted by different ELISA methods has a high priority in the interest of patients' safety (BESLER et al., 2001).

The goal of our work was the monitoring of protein subunit composition of different allergen sources in model food products during food processing to gather more knowledge on the chemical and molecular background of the processes affecting the ELISA results.

Bovine serum albumin (BSA), caseins (CNs), $\beta$-lactoglobulin (BLG), and $\alpha$-lactalbumin (ALA) as milk proteins; ovotransferin (OT), ovalbumin (OVA), ovomucoid (OM), lysozyme (LYS), $\alpha$-livetin, and fosvitin as egg proteins; glycinin and $\beta$-conglycinin as soy proteins; and $\alpha-, \beta-, \gamma-$, and $\omega$-gliadins as wheat proteins were separated, identified from the reference materials used as allergen sources according to the literature (BATTAIS et al., 2005; JIANG et al., 2010; Pesic et al., 2012; JiMÉNEZ-SAiz et al., 2013) and examined.

\section{Materials and methods}

\subsection{Materials}

Baked cookies were produced as processed food matrices, which contained corn starch $(52 \%)$, xanthan gum $(0.6 \%)$, sugar $(18 \%)$, salt $(0.3 \%)$, baking soda $(0.4 \%)$, margarine $(19.6 \%)$, and water (6.6\%). All of the raw materials were commercially available. As allergen sources, whole milk powder (IRMM BCR-380R), whole egg powder (NIST RM 8415), soy flour (NIST SRM 3234), and a gliadin isolate (Sigma Gliadin from wheat, G3375) were used. Cookies contained $2 \%$ milk protein or egg protein or soy protein or gliadin. A multicomponent model product was also produced, which contained $2-2 \%$ of each allergen component. The production procedure was previously published (TöRÖK et al., 2014b). Briefly, in the first step powder mixtures were made with the mixing of the dry components of the recipe and the allergen source(s). In the second step, dough was prepared with addition of margarine and water. After kneading, the raw dough was shaped into cookies. Cookies were baked at $180^{\circ} \mathrm{C}$ for $16 \mathrm{~min}$, a part of the raw dough was freeze-dried.

Samples were taken from the mixture of dry components (powder mixture), from the raw dough, and from the baked cookie as well. The raw dough and the baked cookies were ground at 7000 r.p.m. (Retsch AS 200, Basic). All samples were stored in plastic containers at room temperature until analysis.

\subsection{Defatting procedure}

Ground raw dough and cookie samples were defatted using a Soxtec extractor (Soxtec System HT, 1043 Extraction Unit, Tecator AB, Sweden) according to a procedure described elsewhere (TÖRÖK et al., 2014a).

\subsection{Protein content}

Dumas method (LECO FP-528; ICC Standard No. 167) was applied for the determination of the protein content (using 6.25 as $\mathrm{N}$-conversion factor) of the samples and for checking the homogeneity of protein distribution in the food matrices. 


\subsection{Gel electrophoresis}

The protein compositions of the allergen sources and the model products were analysed by SDS-PAGE according to LAEMMLI (1970), using a stacking gel of 3.75\% and a separating gel of $12 \%$. A Mini Protean 3 Mini-Vertical Electrophoresis System (Bio-Rad Laboratories, Hercules, USA) was applied to perform electrophoretic runs. For sample preparation reducing (with 6\% 2-mercaptoethanol) and non-reducing (without 2ME) extraction buffers were also prepared according to the same protein content ( $400 \mu \mathrm{l}$ buffer to $0.4 \mathrm{mg}$ protein).

\section{Results and discussion}

\subsection{Protein content and homogeneity}

The distribution of protein content in all model matrices was checked and the results show that the protein distribution was homogeneous for all samples (Table 1).

\begin{tabular}{ccc} 
Table & \multicolumn{3}{c}{ Protein content of the corn starch based model products measured by the Dumas method } \\
\hline Sample & Crude protein content (\%) & CV (\%) \\
\hline Cookie - milk & 2.12 & 2.38 \\
Cookie - egg & 2.26 & 1.65 \\
Cookie - soy & 2.03 & 1.35 \\
Cookie - gliadin & 2.10 & 3.08 \\
Cookie - multi & 8.56 & 1.82 \\
\hline
\end{tabular}

\subsection{Matrices containing milk powder}

The ELISA methods usually apply antibodies specific for CNs and/or BLG. The SDS-PAGE patterns (Fig. 1) of native milk proteins are very similar in reducing $(+2 \mathrm{ME})$ and in nonreducing $(-2 \mathrm{ME})$ conditions. The only difference is a protein band on the top of the gel in case of non-reducing conditions, which are the high molecular weight (HMW) aggregates. The theoretical MW of $\alpha_{\mathrm{S} 2-^{-}}, \alpha_{\mathrm{S} 1}{ }^{-}, \beta-$, and $\kappa$-caseins are 25.2, 23.6, 24, and $19 \mathrm{kDa}$, respectively (PESIC et al., 2012). On our gels, the observed molecular masses exceeded the theoretical MWs, which are in accordance with other studies, where the MW of caseins was observed between 25 and $37 \mathrm{kDa}$ (Lisson et al., 2014).

In the raw dough the low MW proteins cannot be identified anymore under non-reducing conditions. The BLG and ALA contents of milk are approximately 10 and 5\%, respectively, so the experienced phenomenon can be explained by the diluting effect of added margarine as well as by fat absorption and binding of proteins. In baked cookies, nearly all protein bands disappeared, merely a light band of caseins could be identified. Besides, under nonreducing conditions, high molecular weight aggregates could be observed on the top of the gel. As these results show, applying of $2 \mathrm{ME}$ is improving the efficiency of extraction (with dissociation of SS bonds), but the whole protein content cannot be dissolved. It means that beside aggregates stabilized by SS bonds, hydrophobic interactions and ionic linkages may also exist between proteins. Furthermore, milk proteins are able to absorb and bind lipids and can form complexes with saccharides through Maillard reactions (GERRARD, 2002). 


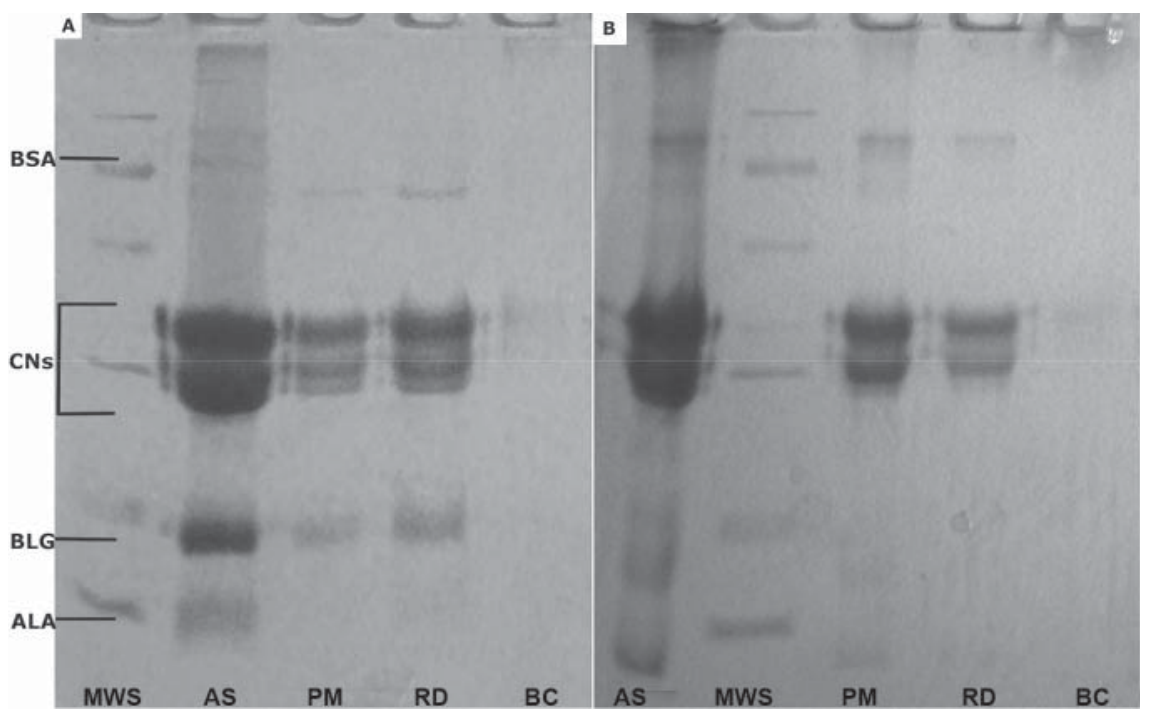

Fig. 1. Electrophoretic patterns of model products containing milk proteins in non-reducing (A) and reducing (B) conditions. MWS: molecular weight standard; AS: allergen source (whole milk powder); PM: powder mixture; RD: raw dough; $\mathrm{BC}$ : baked cookie

\subsection{Matrices containing egg powder}

Target molecules of ELISA methods are OVA and/or OM. The SDS-PAGE patterns of samples containing egg proteins are shown in Fig. 2. The protein band of ovomucoid appeared at $35 \mathrm{kDa}$, however, the molecular mass of OM is reported to be $28 \mathrm{kDa}$ (JIMÉNEZ-SAIZ et al., 2013).

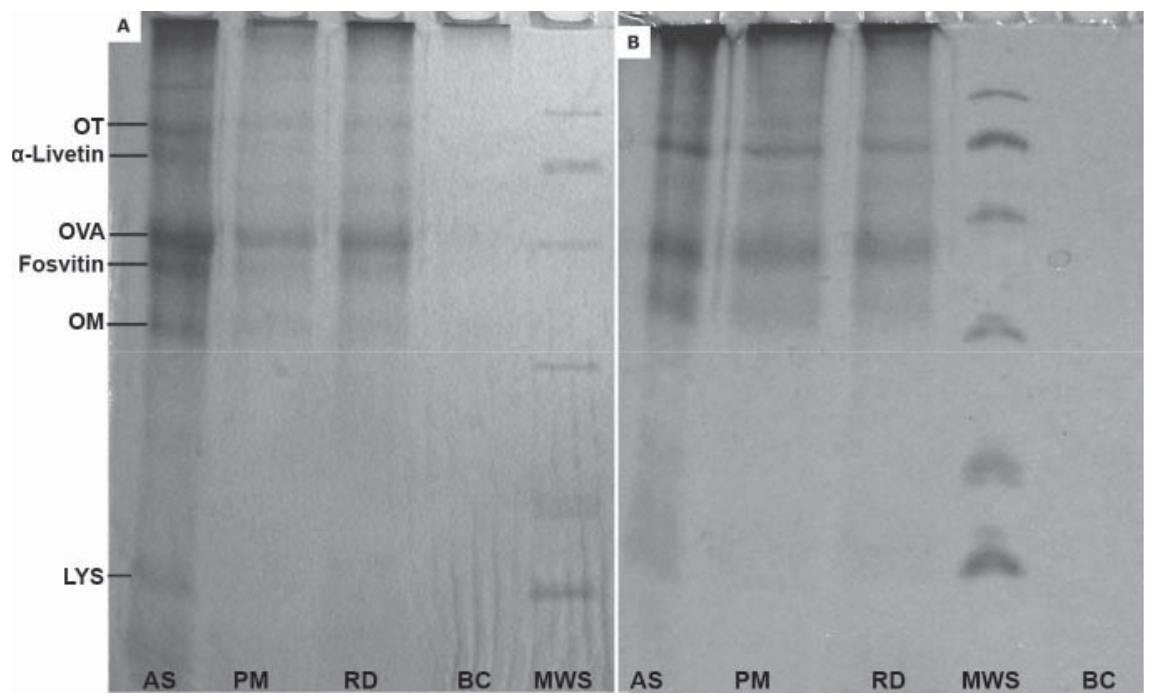

Fig. 2. Electrophoretic patterns of model products containing egg proteins in non-reducing (A) and reducing (B) conditions. MWS: molecular weight standard; AS: allergen source (whole egg powder); PM: powder mixture; $\mathrm{RD}$ : raw dough; $\mathrm{BC}$ : baked cookie 
The PAGE patterns of powder mixture and raw dough do not differ significantly regardless of the presence of a reducing agent. In contrast, the cookie differs significantly. Irreversible solubility loss of egg proteins is a well-known fact. Without 2ME, all of the protein bands disappeared and no aggregate bands could be found on the top of the gel. While using $2 \mathrm{ME}$, the protein band of OVA was visible and a strong aggregate band could also be observed. Since using $2 \mathrm{ME}$ does not improve the solubility significantly, the heat induced aggregates are probably stabilized by rather isopeptide bonds or other crosslinking than SS bonds. Egg proteins can also be glycated and/or they can interact with lipids and lipid oxidation products (GERRARD, 2002; Fu et al., 2010).

\subsection{Matrices containing soy flour}

Antibodies of ELISA methods are usually specific for soy trypsin inhibitor (STI) or not specified soy proteins. The major soy proteins, glycinin and $\beta$-conglycinin, are both heat labile and form aggregates (JIANG et al., 2010). STI is very heat labile and can form aggregates stabilized by SS and/or non-covalent molecular interactions. In the food industry, the common process for inactivation of STI is heat treatment (CHEN et al., 2014).

Powder mixture and raw dough do not differ, all protein bands of soy flour could be found however, high molecular weight bands are appearing under non-reducing conditions and even in reducing conditions in case of raw dough (Fig. 3). It can be explained by complex formation due to hydration and lipid addition. In cookies, the non-reducing electrophoretic pattern shows a loss of low molecular weight proteins, bands are visible only above $50 \mathrm{kDa}$. In contrast, applying $2 \mathrm{ME}$ showed almost all of the protein bands but only with lower intensity, which means that during formation of aggregates some monomer proteins are remaining. Furthermore, it could be observed that the HMW aggregate band in the cookie is similar in intensity to that of the raw dough. Thus, the extraction solution could not dissociate protein-saccharide and protein-lipid complexes (GERRARD, 2002; JIANG et al., 2010).

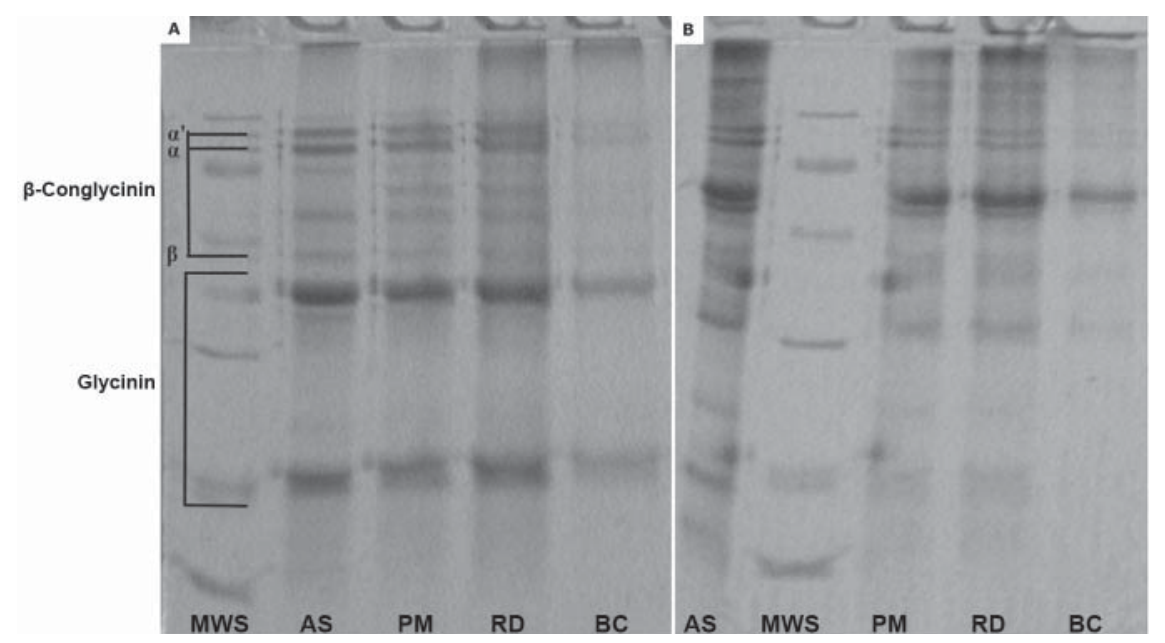

Fig. 3. Electrophoretic patterns of model products containing soy proteins in non-reducing (A) and reducing (B) conditions. MWS: molecular weight standard; AS: allergen source (soy flour); PM: powder mixture; RD: raw dough; $\mathrm{BC}$ : baked cookie 


\subsection{Matrices containing gliadin}

Most of the time, the ELISA methods are applying antibodies specific for $\alpha$-gliadin peptides. R5 is specific for sequence QQPFP, while G12 is raised against the toxic 33-mer peptide (VALDÉs et al., 2003; HALBMAYR-JeCH et al., 2012).

All gliadin subunits could be identified in case of powder mixture and raw dough (Fig. 4). Evaluation of the PAGE patterns of cookies showed that without $2 \mathrm{ME}$ all of the protein bands vanished, while using the reducing agent resulted in significantly improved solubility. Bands of gliadins could be identified but in lower intensity and a HMW aggregate band appeared. Gliadins (mainly $\alpha$-gliadin) are relatively heat stable, but after heat treatment they became extractable only with reducing agent (SINGH, 2005). On the other hand, gliadins are able to form complexes with lipids and saccharides, which can explain the reduced solubility after heating even in reducing condition (MCCANN et al., 2009).

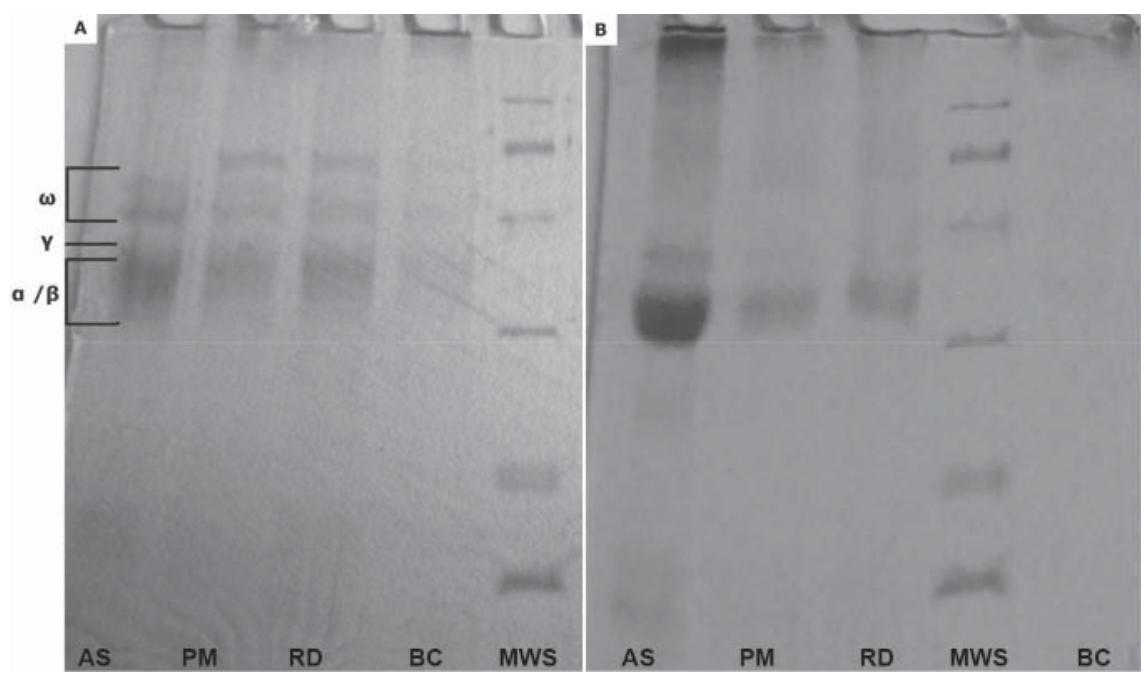

Fig. 4. Electrophoretic patterns of model products containing gliadins in non-reducing (A) and reducing (B) conditions. MWS: molecular weight standard; AS: allergen source (gliadin isolate); PM: powder mixture; RD: raw dough; BC: baked cookie

\subsection{Multi-component matrices}

The electrophoretic pattern of the multi-component powder mixture is a nearly perfect fusion of the patterns of the four single components (Fig. 5).The main protein fractions of single allergen sources could not be separated because of the similar molecular weights. During the food processing, trends and changes similar to the individual matrices could be observed. Without 2ME, bands of low molecular weight proteins disappeared and the intensity of other protein bands also decreased. Reduction led to more intensive protein bands and an intensive aggregate band on the top of the gel. Accordingly, a reduction in solubility is the primary effect of heat treatment. The presence of multi allergen components does not affect significantly the extent of changes. Thus, the importance of any possible interactions between allergenic compounds is negligible compared to the above described effects. 


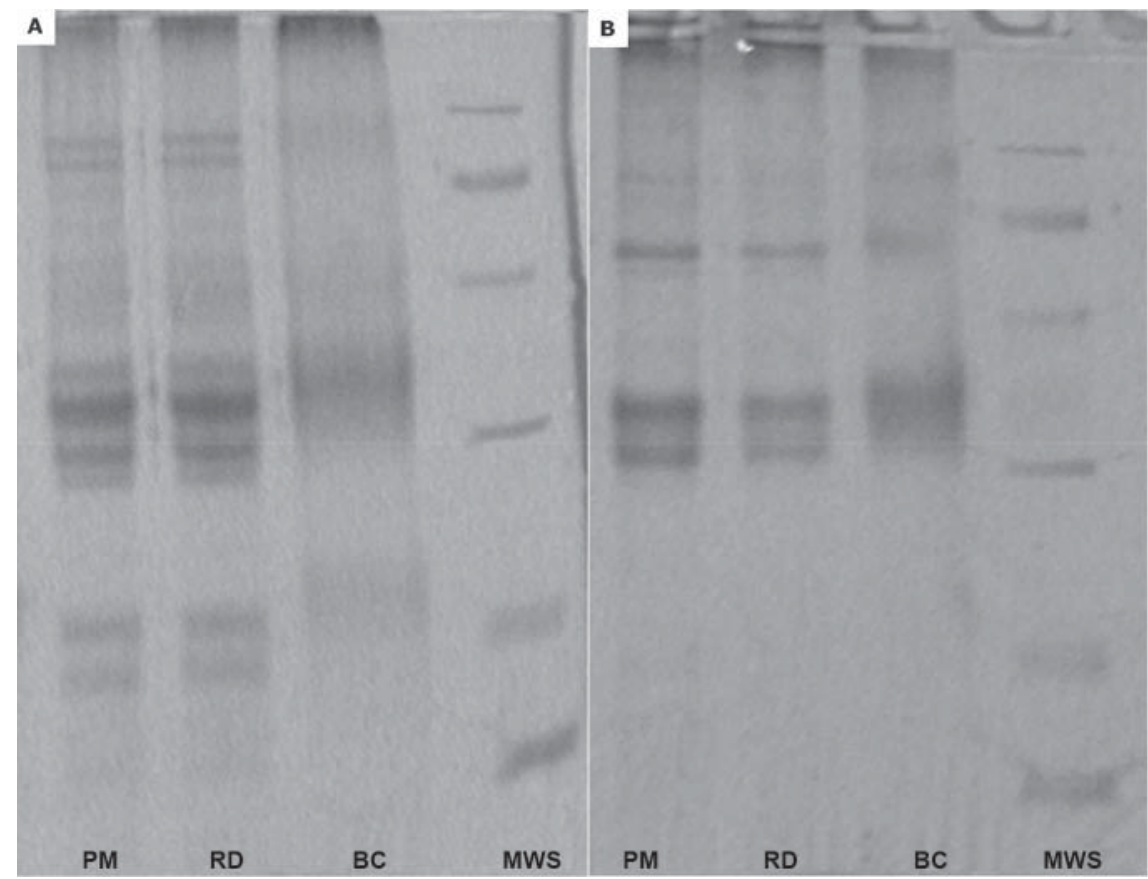

Fig. 5. Electrophoretic patterns of multi model products in non-reducing (A) and reducing (B) conditions. MWS: molecular weight standard; PM: powder mixture; RD: raw dough; $\mathrm{BC}$ : baked cookie

\section{Conclusions}

Changes and behaviour of proteins due to heat treatment are well described in the scientific literature (BESLER et al., 2001; GERRARD, 2002). In our study, modifications of ELISA target proteins were followed during food processing using incurred food matrices.

The SDS-PAGE investigations showed that the protein composition and the amount of subunits are changing during food processing. The main effects could be identified after heat treatment. These changes could be recognized in case of every analyte, but the extent of modifications highly depends on the protein sources. It could be observed that the solubility of proteins decreased in various degrees. In most cases, a commonly used solubilising agent (2ME) was unable to sufficiently improve the solubility of proteins, which means that protein-protein interactions are not exclusively stabilized by disulphide bonds. Proteins can form aggregates during heat treatment through other covalent bonds, like isopeptide bonds, dityrosil crosslinks, etc. (GERRARD, 2002). In real food matrices protein-non-protein interactions can also play a role. Proteins can form complexes with reducing saccharides or fat breakdown products through Maillard reactions. Lipid content of foods may also affect protein solubility due to formation of protein-lipid complexes with absorption or binding (McCANn et al., 2009). Since every observed changes depend on the target protein, development of extraction methods should be specified for each protein in order to improve the accuracy of the analytical method. 
Thus, in case of every analytical method the primary problem is the solubility and consequently the extraction procedures. Solubility of a given protein is depending not only on the protein characteristics but on the other components of food matrices and on the type of processing steps, too. Beside the application of reducing agents, the efficiency of extraction can be improved by a defatting procedure. However, defatting cannot remove bound lipids or removal of bound lipids can also lead to removal of proteins. Considering the variety of proteins, food matrix composition and processing steps, it is hardly conceivable to develop a general extraction protocol that can extract every protein from every food matrix. This can be a limitation factor during development of multi-component analytical methods.

Most of the research efforts deal with protein isolates or preparations to investigate the thermal modifications of proteins. According to our results, the behaviour of proteins highly depends on the complexity of food matrices. Using the same extraction buffers for ELISA and SDS-PAGE measurements is not possible, because i) the composition of buffers packed to ELISA kits is not known and ii) the circumstances of these measurements are different (i.e. addition of SDS). On the other hand, our research work shows that even with the commonly used reagents (i.e. 2-mercaptoethanol), most of the proteins remain insoluble after heat treatment. Thus, the significant solubility decrease caused by protein denaturation can be the major cause of weaker performance (primarily the accuracy and recovery) of the immunoanalytical methods. It also seems proven that the currently applied extraction protocols in the studied kits (except for some gluten ELISA kits) are not able to improve the solubility of the target proteins or protein complexes in processed matrices.

As the possible aggregations and complex formations highly depend on the protein source and also on the target protein, it is obvious that the development of a universal solution is very complicated. Due to this reason, we think that without the improvement of protein extraction from raw and processed materials as well as without the selection of more heatstable target proteins, the analytical performance of ELISA methods in processed foods cannot be significantly improved. Compared with the solubility issue, the other possible effects on method performance seem negligible.

A further result of this study is the development of the laboratory scale model matrices, which ensure good opportunity for scientific investigation of the observed phenomena.

This research is related to the scientific goals of MoniQA Association and the national project "Development of quality orientated, harmonized educational and $\mathrm{R}+\mathrm{D}+\mathrm{I}$ strategy and operational model at the Budapest University of Technology and Economics" (ÚMFT TÁMOP-4.2.1/B-09/1/KMR-2010-0002).

\section{References}

Battais, F., Courcoux, P., Popineau, Y., Kanny, G., Moneret-Vautrin, D.A. \& Denery-Papini, S. (2005): Food allergy to wheat: differences in immunoglobulin E-binding gproteins as a function of age or symptoms. $J$. Cereal Sci., 42, 109-117.

Besler, M., Steinhart, H. \& Paschke, A. (2001): Stability of food allergens and allergenicity of processed foods. J. Chromatogr. B, 756, 207-228.

Blais, B.W., Gaudreault, M. \& Phillippe, L.M. (2003): Multiplex enzyme immunoassay system for the simultaneous detection of multiple allergens in foods. Food Control, 14, 43-47.

Bugyi, Zs., NAgy, J., TÖRÖK, K., HAJAs, L. \& TÖMÖSKÖZI, S. (2010): Towards development of incurred materials for quality assurance purposes in the analysis of food allergens. Anal. Chim. Acta, 672, 25-29. 
Chen, Y., Xu, Z., Zhang, C., Kong, X. \& Hua, Y. (2014): Heat-induced inactivation mechanisms of Kunitz trypsin inhibitor and Bowman-Birk inhibitor in soymilk processing. Food Chem., 154, 108-116.

EU (2011): Regulation No 1169/2011 of the European Parliament and of the Council. OJ, 304, 18-63.

Fu, T., MaKs, N. \& Banaszewski, K. (2010): Effect of heat treatment on the quantitative detection of egg protein residues by commercial enzyme-linked immunosorbent assay test kits. J. Agr. Food Chem., 58, 4831-4838.

GerRard, J.A. (2002): Protein-protein crosslinking in food: Methods, consequences, applications. Trends Food Sci. Tech., 13, 391-399.

Halbmayr-Jech, E., Hammer, E., Fielder, R., Coutts, J., Rogers, A. \& Cornish, M. (2012): Characterization of G12 sandwich ELISA, a next-generation immunoassay for gluten toxicity. J. AOAC Int., 95, 372-376.

Heick, J., Fischer, M. \& Popping, B. (2011): First screening method for the simultaneous detection of seven allergens by liquid chromatography mass spectrometry. J. Chromatogr. A., 1218, 938-943.

JiANG, J., XIONG, Y. \& CHEN, J. (2010): pH shifting alters solubility characteristics and thermal stability of soy protein isolate and its globulin fractions in different $\mathrm{pH}$, salt concentration, and temperature conditions. J. Agr. Food Chem., 58, 8035-8042.

Jiménez-SAiz, R., López-Expósıto, I., MoLina, E. \& López-Fandino, R. (2013): IgE-binding and in vitro gastrointestinal digestibility of egg allergens in the presence of polysaccharides. Food Hydrocolloids, 30, 597-605.

LAEMmLi, V. (1970): Cleavage of structural proteins during the assembly of the head of bacteriophage T4. Nature, 227, 681-684.

Lisson, M., Lochnit, G. \& ERHARDT, G. (2014): In vitro gastrointestinal digestion of bovine $\alpha_{\mathrm{S} 1}$ and $\alpha_{\mathrm{S} 2}$-casein variants gives rise to different IgE-binding epitopes. Int. Dairy J., 34, 47-55.

McCann, T.H., Small, D.M., Batey, I.L., Wrigley, C.W. \& Day, L. (2009): Protein-lipid interactions in gluten elucidated using acetic-acid fractionation. Food Chem., 115, 105-112.

Pesic, M.B., Barac, M.B., Stanojevic, S.P., Ristic, N.M., Macej, O.D. \& Vrvic, M.M. (2012): Heat-induced caseinwhey protein interactions at natural $\mathrm{pH}$ of milk: A comparison between caprine and bovine milk. Small Ruminant Res., 108, 77-86.

Singh, H. (2005): A study of changes in wheat protein during bread baking using SE-HPLC. Food Chem., 90, 247250.

TAYLOR, S.L. \& HeFLE, S.L. (2001): Food allergies and other food sensitivities. Food Technol., 55, 68-83.

TÖRÖK, K., HAJAS, L., BUGYI, Zs., BALÁZs, G. \& TÖMÖSKÖZI, S. (2014a): Investigation of the effects of food processing and matrix components on the analytical results of ELISA using an incurred gliadin reference material candidate. Acta Alimentaria, DOI:10.1556/AAlim.2014.0018, 44, 390-399.

TöröK, K., Horváth, V., Horváth, Á., Hajas, L., Bugyi, Zs. \& TÖMÖsKöZI, S. (2014b): Investigation of incurred single and multi-component model food matrices for determination of food proteins triggering allergy and celiac disease. Eur. Food Res. Technol., DOI: 10.1007/s00217-014-2289-6, 239, 923-932

ValdÉs, I., Garcia, E., Llorente, M. \& Méndez, E. (2003): Innovative approach to low-level gluten determination in foods using a novel sandwich enzyme-linked immunosorbent assay protocol. Eur. J. Gastroen. Hepat., 15, $465-474$. 